\title{
Tweets Flooded in Bandung 2016 Floods: Connecting Individuals and Organizations to Disaster Information
}

\author{
Anang Dwi Santoso \\ Departement of Public Administration, Faculty of Social and Political Sciences, Universitas Sriwijaya, Indonesia
}

Received: 2018-07-13

Accepted: 2019-08-19

\section{Keywords:}

disaster communication;

social media;

natural disaster;

flood

Correspondent Email: anangdwi@fisip.unsri.ac.id

\begin{abstract}
In a natural disaster, social media has been widely used as one of the primary communication channels to supplement the traditional ones. However, there is a lack of empirical research analyzing this evidence, therefore the purpose of this study is to identify the information shared by Twitter users during the Bandung Flood of 2016 based on period, location, and account ownership. A dataset of 754 tweets was acquired using the NCapture feature in NVivo for content analysis. The study found that social media has significant benefits primarily when sharing information from affected areas to communities outside the region. In more detail, Twitter is used by $28.4 \%$, primarily by those not impacted by the flood, to express good wishes and memorializing. It is because people in the affected area shared firsthand information (23.8\%) to them. Then, in addition to citizens, media, NGOs, government, and community leaders who have been found in earlier studies, actors such as civil service organizations $(2.9 \%)$ and political parties $(0.5 \%)$ have also participated in disaster relief.
\end{abstract}

(C) 2019 by the authors. This article is an open access article distributed under the terms and conditions of the Creative Commons Attribution(CC BY NC) licensehttps://creativecommons.org/licenses/by-nc/4.0

\section{Introduction}

Social media became one of the important communication channels in the period before, during, and after the disaster (Murthy \& Longwell, 2013; Simon, Goldberg, Aharonson-Daniel, Leykin, \& Adini, 2014; Takahashi, Tandoc, \& Carmichael, 2015). However, studies that seek to prove the usefulness of social media in natural disasters are still limited (Alexander, 2014; Kumar, Barbier, Ali Abbasi, \& Liu, 2011). Although there have been several studies that have found mechanisms for the use of social media for disaster management, the mechanisms of social media used to support this important information delivery process remain unclear (Crooks, Croitoru, Stefanidis, \& Radzikowski, 2013). Aside from that, Takahashi et al. (2015) revealed that most research focuses too much on the use of social media by institutions who forget that with social media every user is free to disseminate information.

In natural disasters, social media plays a role in increasing community participation in disaster management through the process of exchanging information from the public to the public (Simon et al., 2014). In disaster situations, people use social media to gather and share disaster-related information (Sakaki, Okazaki, \& Matsuo, 2010). Furthermore, Xiao, Huang, and Wu (2015) divide social media functions into three areas: disseminating information, raising awareness of the disaster situation, and completing the official channels provided by the government. Based on these benefits, the information's quality becomes very important during the disaster because the community will continue to seek and share information when the disaster occurred. In addition, Caragea, Squicciarini, Stehle, Neppalli, and Tapia (2014) said that there are two important things used to see the quality of information. Those are: where users use social media, and what information is provided by users.

Social media then becomes more responsive and develops new technologies to improve the effectiveness of its use during disasters. In 2013, Twitter launched Twitter Alerts, a function designed to prioritize information from credible organizations during disasters. Facebook also launched a similar feature known as Security Check, which can be used to ensure that users survive during a disaster. By seeing the importance of Twitter's role in disaster management, the information conveyed through tweets becomes very important.

Mirza (2003) finds that developed and developing countries have different capabilities in every stage of disaster management. It will then affect the amount of damage as well as reconstruction attempts. Zhu and Kindarto (2016) also show that developing countries have different uses of technology and access to the Internet. Both of these are interesting reasons for researching the theme of social media beneficiaries in developing countries.

The role of social media in disaster management is still only understood in a limited way (Binder, 2012). Most studies discussing this theme still focus only on 
the organizational perspectives (Freberg \& Palenchar, 2013; Lundgren \& McMakin, 2009). Some studies are also limited in determining the effectiveness and ineffectiveness of social media use during a crisis (Takahashi et al., 2015). It is also supported by the government that is now becoming aware of the potential use of social media in crises (Beneito-Montagut, Anson, Shaw, \& Brewster, 2013).

Alexander (2014) adds that studies about social media in disaster management are more about (1) how social media is used in crises; (2) the views and opinions of managers working in disaster management agencies as well as journalists on the integration of new media with traditional media; and (3) how social media interacts with traditional media in providing disaster information. On the other hand, studies on the use of social media by the public are still quite rare (Alexander, 2014; Takahashi et al., 2015). Moreover, they also added that there is a need to understand how social media is used from a community perspective.

Looking at some of the research above, this study then proposes a more comprehensive approach to view Twitter as an effective channel for conveying information about disasters and increasing public participation in the disaster management processes. This paper aims to explore the use of social media during a disaster. The author will take tweets on Twitter and group them into each potential function of social media in a disaster. In contrast to previous studies that ignore local languages (Takahashi et al., 2015), this paper accommodates local, national, and English languages to provide a more complete picture of the situation for disaster events. The author will also see the spread of time in the use of social media and its location. By looking at the importance of information in a disaster, the authors will also identify the sources of information coming (community, journalist, government).

In a study to see social media used by the public, one of the things to look at is the typology of social media use. Qu, Huang, Zhang, and Zhang (2011) developed an information category on social media during the earthquake in China. A similar study was also conducted by Kongthon, Haruechaiyasak, Pailai, and Kongyoung (2014) on the flood disaster in Thailand. Houston et al. (2014) conducted a literature study to develop a typology of social media use in a disaster and found 15 uses of social media in disasters. The framework created by Houston et al. (2014) has also been tested by Takahashi et al. (2015) in a similar study in the case of Typhoon Haiyan in the Philippines. This study will then use that framework to see typical information obtained or wanted to get Twitter users during a disaster.

Subsequently, the geographic component also affects the information provided during a disaster (Takahashi et al., 2015). Miyabe, Miura, and Aramaki (2012) found that people outside the disaster area tended to offer more information about the disaster and spread abstract images since people affected directly or in disaster areas tend to communicate directly with others with a reply-based tweet mechanism.

Finally, Binder (2012) observed no connection between tweets containing disaster information with time (before, during, and after). Research showing that there is different information submitted by Twitter users in the period before, when and after the disaster is very difficult to find (Takahashi et al., 2015).

Considering several important aspects of disaster communication such as (1) shared information; (2) the actors who shared the information; and (3) the geographic information giver and information timing were distributed, the authors formulated the following questions:

RQ1: How does society use social media as an effective medium in disaster communication?

RQ2: Based on account ownership (the general public, government, NGOs, etc.), for what purposes do these actors use social media for disaster communication?

RQ3: When viewed from its location (the disaster area and outside the disaster area), is social media used in a different way?

RQ4: Are there any typological differences regarding Twitter content before, during, and after the disaster?

Given that the function of social media in natural disasters is unclear, this study offers empirical evidence regarding the use of social media during the Bandung Flood that took place on October 2016 by classifying various types of users, places, and periods of disaster. The contributions of this study are threefold. First, the author provides and compares the variations of information shared by the various users to understand the nature of disaster communication in social media. Second, this paper presents shared information by users outside and at an affected location, especially to learn information related to the severity of the disaster and the assistance needed by victims. Finally, this study demonstrates information shared in the period before, during, and after disasters that have not been clear in previous studies.

\section{The Role of Social Media in Disaster Communication}

Social media can be used to strengthen the communication process before, during, and after a disaster occurs (Houston et al., 2014). Throughout the recent years, social media has evolved from passive media into a tool that can distribute information containing warnings, help-seeking information, and information to raise situational awareness (Lindsay, 2011). 
a. dissemination of information in real-time.

The research of Keim and Noji (2011) in the 2010

Haiti Earthquake shows that information about disasters appeared first on social media. The study shows that there is the immediate dissemination of information to many people through social media. Compared to traditional media that provides one-way communication, social media can provide mutual mechanisms between users (Xiao et al., 2015). While waiting for news from professional agencies, individuals can receive firsthand information and share that information through social media.

b. Raising situational awareness

Policymakers use social media to observe emerging situations by monitoring people in potentially disastrous areas and presenting real-time, geo-referenced information before then informing them (Xiao et al., 2015). Kumar et al. (2011) designed an application called TweetTracker to search, analyze, and monitor tweets in order to access disaster relief. This app can separately report the location where the tweets were created, support keyword searches, and generate specific keywords that the user wants. Such information is obtained from social media and can help policymakers understand the bigger picture of emergencies in real-time.

c. Communication support

Social media becomes an informal information channel that can develop quickly. Supporting information represents the power of the community through the sharing of information in emergencies when traditional media provides insufficient information regarding the conditions occurring at the site of a disaster (Xiao et al., 2015).

\section{The Methods}

This study examined the Flood Disaster Case in Bandung. This location is supported by several things: (1) Bandung has a unique policy related to the use of social media; the Mayor of Bandung, Ridwan
Kamil, through Mayor Regulation No. 1265 of 2015, establishes social media as one of the strategic forms of communication in maintaining the relationship with the community, increasing accountability and gaining public aspirations. (2) Ridwan Kamil has successfully conducted citizen engagement in various government programs through Twitter; for example, by encouraging people to actively convey complaints related to public services through photo evidence. This research was conducted by taking a tweet from Twitter. Twitter was chosen because it became one of the most popular social media platforms available today. Aside from that, Twitter is developing apps to increase its role in a disaster event. Twitter also limits its users to write 280 characters, which encourages users to send concise information.

The population in this research is the tweets searched through the advanced search menu. The sample in this study was obtained by taking tweets via the Nvivo application. With the following period:

This research was conducted using a method of analysis with the rule-based classification technique. This technique was used to identify the types of messages submitted by Twitter users in the event of a disaster. This process consists of several steps that include:

a. Data collection: The data collection process is done by searching for keywords as described in Table 1. Then the author uses the help of Nvivo software that can help the data collection process. Through this software, writers obtain data in the form of account, name, followers, following, tweet, location, number of retweets. By using these keywords, the author obtained 1,318 tweets that will be sampled in this research. Tweets were then reduced to the criteria recommended by Konghton (2014). Based on these criteria, the author eliminated the HTML link, RT (Retweet) command, and Hashtag (\#). Tweets that are identical to different accounts will also be expanded on. Finally, the author has 753 tweets ready to be analyzed.

Table 1. Determining the period of disaster

\begin{tabular}{|c|c|c|c|}
\hline Period & Date & Time & Hashtag Time Date or keywords used \\
\hline Before Disaster & October 24th, 2018 & $08.00-11.29$ & Rain; heavy rain (using specific areas) \\
\hline During Disaster & October 24th, 2018 & $11.30-14.00$ & $\begin{array}{l}\text { \# B a } n \text { j i } \mathrm{r} \text { B a } \mathrm{n} \text { d } \mathrm{u} \text { g } \\
\text { (\#Bandungflood) \#PrayforBandung; } \\
\text { help and victims (using specific areas) }\end{array}$ \\
\hline After Disaster & $\begin{array}{l}\text { October 24th, } 2018 \\
\text { October 25th, } 2018\end{array}$ & - 14.00-14.00 (24 Hours) & $\begin{array}{l}\text { \# FloodBandung \# PrayforBandung, } \\
\text { help and victim (using specific area) }\end{array}$ \\
\hline
\end{tabular}


Table 2. Category of information in disaster communication

\begin{tabular}{|c|c|}
\hline Category & Description \\
\hline Reporting on the situation & Includes providing and receiving disaster preparedness and war \\
\hline $\begin{array}{l}\text { from a personal perspective } \\
\text { Reporting on the situation } \\
\text { (secondhand perspective) }\end{array}$ & $\begin{array}{l}\text { and informing others about disaster conditions and locations. } \\
\text { Includes disaster detection, documenting what's happening, and sending out } \\
\text { disaster news. }\end{array}$ \\
\hline Requesting help & Requesting help during and after a disaster. \\
\hline Coordinating relief efforts & $\begin{array}{l}\text { Increase disaster awareness, donations, identify ways to help or volunteer, and } \\
\text { provide disaster response information. }\end{array}$ \\
\hline Providing mental counseling & and receiving psychological and mental health assistance. \\
\hline Criticizing the government & for dealing with disasters. \\
\hline $\begin{array}{l}\text { Expressing good wishes and } \\
\text { memorializing }\end{array}$ & Expressing emotions, cares, hopes, and commemorating victims. \\
\hline Discussing causes & Discussing causes include scientific, religious, and other causes. \\
\hline $\begin{array}{l}(\mathrm{Re}) \text { connect community } \\
\text { members }\end{array}$ & Discuss how the process of creating communities after a disaster occurs. \\
\hline
\end{tabular}

Source: (Takahashi et al., 2015)

b. Analysis and classification of data: The author will then perform the analysis by classifying the tweet contents according to the following categories: (1) Content analysis: one of 15 typology tweet contents (See Table 2); (2) Category of organizations/individuals (Organization: mass media, government, NGO, etc. and individuals include: politicians, community, and artists); (3) location: disaster area or outside disaster area; (4) Time before disaster, during disaster, or after disaster.

\section{Bandung Flood Profile}

High-intensity rain flooded the city of Bandung on Monday afternoon (24/10/2016), causing major roads in Bandung to become submerged underwater. The area of Pasteur was the most severely affected. Along with the main road, the water had rushed into the road like a river. The area in Jalan Pasteur was flooded to a height of $160 \mathrm{~cm}$. Also, Jalan Pagarsih had a 150-cmhigh flood and Jalan Nurtanio had waters as high as 120 $\mathrm{cm}$. The water flowed quickly and all urban drainage overflowed. Urban drainage channels were not able to contain the flow of the water, thus resulting in a flood. Cars and motorcycles that were on the road were also affected by the flood. Vehicles parked at the BTC Mall were hit as well. Even some cars were dragged down by the flood similar to what would occur by a small tsunami. Based on the preliminary reports from BPBD West Java Province, floods caused hundreds of houses to flood. There were houses damaged by the floods on the banks of the Cilimus River. Floods also broke down the fence SMAN 9 Bandung, flooding the school.

\section{Results and Discussion}

The first objective of this study is to analyze the information distributed during the Bandung Flood that took place on October 2016. The research findings show that the most frequently shared information is memorializing, which is used as much as $28.4 \%$. This category includes expressions of sympathy and well wishes for the flood victims. The most widely disseminated information is the firsthand report. This information is shared by as much as $23.8 \%$ of the tweets that were collected. In this category, Twitter users share up-to-date information based on the real conditions in the field. This category also consists of information provided by a user to other users about their situation. Then, netizens also use Twitter to criticize the government's performance in disaster management, tweeting $9.3 \%$ of the information collected. In this category, users use Twitter as a medium to provide input to the government about its performance in disaster management.

Then, the categories that are rarely found in Bandung October 2016 floods such as coordinating relief effort, requesting help, and providing mental counseling. To elaborate, only $1.2 \%$ of users use Twitter to coordinate relief efforts. The information included in this category includes identifying the needs of the flood victims, the opening and receipt of donations, and the coordination of volunteers. Moreover, information containing requests for assistance is also rarely found during the Bandung Flood of October 2016. Of the total tweets that were obtained, only $1.2 \%$ of tweets have this information. Finally, the least information found in this disaster is the provision of mental counseling for flood victims. This information is only found in as much as $0.3 \%$ of tweets, because the October 2016 Bandung Flood is not a severe disaster so tweets for these three categories are rarely found. 
Table 3. Tweet categories that were shared during the Bandung Flood on October 2016

\begin{tabular}{ll}
\hline Shared tweets & Percentage \\
\hline Memorializing & $28.4 \%$ \\
Reporting (firsthand) & $23.8 \%$ \\
Criticizing government performance & $9.6 \%$ \\
Requesting information & $9.3 \%$ \\
Discussing causes & $8.8 \%$ \\
Reporting (secondhand) & $5.6 \%$ \\
Discussing future solution & $4.1 \%$ \\
Appreciate government performance & $3.6 \%$ \\
Clarifying information & $3.5 \%$ \\
Coordinating relief effort & $1.2 \%$ \\
Requesting help & $1.2 \%$ \\
Uncategorized & $0.8 \%$ \\
Providing mental counseling & $0.3 \%$ \\
\hline
\end{tabular}

Source: secondary data processing, 2017

Table 4. Actors and information distributed during the Bandung Flood October 2016

\begin{tabular}{lll}
\hline Actor & Percentage & Most tweeted \\
\hline Citizen & $84.9 \%$ & $\begin{array}{l}\text { Firsthand Report } \\
\text { Media }\end{array}$ \\
CSO, NGO, and & $7.8 \%$ & $\begin{array}{l}\text { Firsthand Report and Secondhand } \\
\text { Report }\end{array}$ \\
Private Sector & $3.5 \%$ & $\begin{array}{l}\text { Memorializing and Coordinating relief } \\
\text { effort }\end{array}$ \\
Government & $2.9 \%$ & Firsthand Report \\
Political party & $0.5 \%$ & Memorializing \\
Public figure & $0.4 \%$ & Memorializing \\
\hline Source: secondary data processing, 2017
\end{tabular}

The second objective of this research is to see the actors who participated in Bandung Flood of October 2016. By looking at Twitter bios, this research found that Twitter users in this disaster include citizen, media, $\mathrm{CSO}, \mathrm{NGO}$, private sector, government, and political party. The research findings show that Twitter users in the Bandung Flood of October 2016 dominated the community that had as much as $84.9 \%$ of the overall tweets. Based on that information, people tend to use Twitter to share firsthand information.

Other actors found in this study were $7.8 \%$. Actors belonging to this category share information containing both firsthand and secondhand reports. Usually, they send journalists to the disaster site and provide an overview of the disaster location. They then publish news produced by their company. In more detail, the media includes news agencies, television, and radio, both locally and nationally. Later, actors like CSOs, NGOs, and private sector organizations also participated in this disaster. The information sought by these accounts is memorializing and coordinating the relief effort.
Unfortunately, the government is still lacking a contribution to the flood disaster; there are only $2.9 \%$ of the tweets it shares. Judging from the shared content, governments tend to use their social media accounts to share firsthand information that includes the actual picture of flood conditions. In this category, the government includes government agencies, mayors, and government employees. Additionally, there are also political parties and public figures that are equally less than $1 \%$. Both use Twitter to express grief for disaster victims.

The third objective of this study is to look at the amount of information distributed in the period before, during, and after the disaster occurred. Before the disaster, as many as $4 \%$ of users used Twitter to do a firsthand report. In more detail, the users stated that at the time there was heavy rain in Bandung and the surrounding areas. A netizen has voiced his concerns a few hours before the floods occurred. The government should use this information to reduce disaster risk. 
Table 5. Disaster and tweet periods with the most share

\begin{tabular}{lll}
\hline Period & Percentage & Tweets with most shares \\
\hline Before & $4 \%$ & Firsthand report \\
During & $75 \%$ & Firsthand report and Memorializing \\
After & $21 \%$ & Memorializing
\end{tabular}

Source: secondary data processing, 2017

Table 6. Location and different information shared

\begin{tabular}{lll}
\hline Location & Percentage & Shared information \\
\hline Inside & $45 \%$ & Firsthand report \\
Outside & $55 \%$ & Memorializing \\
\hline
\end{tabular}

Source: secondary data processing, 2017

The number of tweets continues to increase when floods occur. Of the collected tweets, $75 \%$ was tweeted during the disaster, and the increasing number of tweets is due to the use of \#banjirbandung (\#bandungflood) and \#prayforbandung. This then causes a reaction from people outside the disaster area to respond to the information. The two most commonly found types of information from this category are firsthand reports and memorializing. Reduced flooding is also followed by a decrease in the number of tweets. Regarding numbers, there are $21 \%$ of tweets distributed within 24 hours of flooding, then, judging by the information shared, most tweets contain condolences.

Finally, this study illustrates the differences of information within and outside the disaster area. By using the GeoTag feature on Twitter, this study found that the number of tweets from inside and outside the disaster area is almost comparable. The study found that $45 \%$ of tweets was shared by people in the disaster site, while the rest were coming from outside the disaster site.

Then, judging from the information shared, there is a tendency to use different Twitters in both locations. In a disaster location, Twitter users tend to share tweets containing firsthand reports. Also, Twitter users share information about flood conditions. Unlike the users in a disaster area, users outside the disaster area tend to use Twitter to express their condolences and hopes for disaster victims.

Communication is a crucial component in every stage of disaster management. Effective disaster communication will reduce the impact of disasters, while poor disaster communications will increase the severity of the disaster (Houston et al., 2014). Therefore, the development of effective disaster communication should be the priority of the actors involved in disaster management.

The development of communication technologies, such as social media, allows for an increased quality of disaster communications as they offer increased capacity, reliability, and interactivity (Jaeger et al., 2007). Therefore, this study aims to provide a comprehensive overview of the use of social media in times of natural disasters.

This study proves that social media has the power to share information in real-time during a natural disaster. In disaster situations, users offer an illustration of the severity of the disaster and the number of casualties to the assistance needed by the victims. This study is in line with the findings of Vieweg, Hughes, Starbird, and Palen (2010), who found that social media can assist the communication process by connecting individuals and organizations with disaster information.

Furthermore, social media can also be used to signal and detect disaster by using the user's social media status. As in the case of this particular flood, users have mutually detected and predicted that heavy rain would cause flooding. This finding is in line with Houston's et al. (2014) findings. The study found that in the case of the Virginia earthquake, some individuals reported that they experienced an earthquake. The US government then used the location feature in each tweet to map disaster locations.

In the case of the Bandung Flood, Twitter users shared disaster warnings. For example, some Twitter users shared information about the streets of Bandung at the moment when it was flooded so that other users could avoid the road. This finding is in line with the results of Rive, Hare, Thomas, and Nankivell (2012), who found that before the disaster came, social media users could provide and share disaster warnings.

Another benefit of social media from the Bandung Flood Case of October 2016 was that users could share the conditions and locations of disasters. In more detail, Twitter users shared their location and news of themselves to other users. This is in line with the findings of Shklovski, Palen, and Sutton (2008), who found that after Hurricane Katrina, the "safe list" website released information on the list of survivors in the disaster. The study also confirmed that social media is the right medium to open and accept donations as well as organize volunteers to help the disaster management process. In the case of the Bandung Flood in October 2016, victims and volunteers located in the disaster 
area provided information regarding the equipment needed by adding \#BanjirBandung (\#BandungFlood) and \#PrayforBandung. Twitter users then responded to the information by holding an open donation. This is in line with the findings of Lobb, Mock, and Hutchinson (2012), who found that the more social media generated messages about earthquakes in Haiti, the disaster victims received more donations.

Later, the study also found that social media is used by its users to express emotions, concerns, and prayers to disaster victims. Social media allow users to receive disaster information and respond to it either by giving help or condolences (Houston et al., 2014). The findings of this study are in line with Liu et al., (2008) who found that people in Africa provided memorial messages on social media in response to the tornado disaster in the US.

As expressed by Houston et al. (2014) that the post-disaster period is the time when individuals discuss the causes of natural disasters, this study also found that Twitter users discussed the cause of the incident. Twitter users generally suspected that the cause of Bandung flood was due to the lack of green open space. Some people also blame the Mayor of Bandung as the person responsible for the event. It caused a commotion between the blame and defended the Mayor of Bandung. Some netizens defended the Mayor of Bandung by praising his performance of handling the flood well in such a short time. Meanwhile, others criticized the policies that are considered not pro-environment. This finding is in line with the results of the Bucher (1957) study that the process of discussing the causes of flood induce discordance and hostility in society.

As discussed earlier, this research uses a framework created by Takahashi et al. (2015) to read the information that users shared via Twitter during the Bandung Flood of October 2016. This study finds three new categories that may enrich that framework. These categories include discussions on policies that should be conducted by the government in the future, appreciation of government performance, and clarification of fake information as a result of the emergence of false information.

Viewed from the user perspective, the results of this study have both similarities and differences with the results of the research done by Takahashi et al. (2015). This study confirms the findings of the study that the community was a dominating actor during the Bandung Flood of October 2016. This research also finds the presence of traditional media on social media, such as television, radio, and news agency both local and national, government, NGO, and public figure. The new findings in this research are the presence of a civil society organization, the private Rochester, and public figures who also attended the Bandung Flood in October 2016.

By using the GeoTag feature, this research found that users in a disaster area tended to use Twitter to share a firsthand report. Individuals within the disaster area can share information from their experience and vision to the people outside the disaster site (Houston et al. 2014). The results of this study are in line with the findings of Lock, Cooke, and Jackson (2013). However, this study differs from the findings of Takahashi et al., (2015) who found that individuals in disaster sites tend to use Twitter to share secondhand reports.

\section{Conclusion}

This study examines the strength of social media as a medium of disaster communication during the Bandung Flood of October 2016. This study demonstrates that social media platforms are widely used to express condolences and give firsthand reports. This study also found that different users did not communicate different information in a natural disaster. Furthermore, the primary use of social media by citizens and government entities is to distribute firsthand reports while political parties and public figures utilize social media to express condolences. Media, such as newspapers and radio, use social media to share firsthand and secondhand reports. For CSOs, NGOs, and the private sector, social media is used for expressing condolences. Judging from the period, before the occurrence of a disaster, Twitter was utilized to share the firsthand report. Meanwhile, during the disaster, users used social media to share firsthand reports and express condolences. Lastly, after the disaster, Twitter users utilized social media to express condolences. Communities outside the disaster area responded to the information by giving condolences and well wishes to the people affected by the disaster and providing assistance in the form of goods needed by the victims. In addition, the public can also utilize social media to discuss the causes of and solutions to this disaster.

This study has practical and academic implications. From a practical point of view, this study confirms that the framework created by Houston et al. (2014) and simplified by Takahashi et al. (2015) can be used to improve the quality of disaster communication. Academically, this research provides additional information on the use of social media in disasters, such as discussions about policies that must be conducted by the government in the future, appreciation of government performance, and the clarification of fake information as a result of the emergence of false information. Later, the study also found that there are some actors, such as civil society organizations, the private sector, and political parties, who also use social media to convey disaster information. Finally, this research offers the idea to use the Twitter GeoTag feature to separate tweets from within and outside of the disaster area.

This study has several limitations. First, this research only uses a single case study. Subsequent 
research can use several cases to compare disaster communication at different locations. Then, this research uses keywords such as rain, flood, help, \#PrayforBandung, and \#BanjirBandung. There may still be other keywords to optimize search results. Future research may expand the keywords in order to increase the number of tweets analyzed. Finally, this research takes data from Twitter. Various social media platforms, such as Facebook and Instagram, can be used in future research.

\section{References}

Alexander, D. E. (2014). Social Media in Disaster Risk Reduction and Crisis Management. Science and Engineering Ethics, 20(3), 717-733. https://doi. org/10.1007/s11948-013-9502-z

Beneito-Montagut, R., Anson, S., Shaw, D., \& Brewster, C. (2013). Governmental Social Media use for Emergency Communication. In Governmental SM use for Emergency Communication (pp. 828-833).

Binder, A. R. (2012). Figuring out \#fukushima: An initial look at the functions and content of US twitter commentary about nuclear risk. Environmental Communication, 6(2), 268-277. https://doi.org/10.1080/17524032.2012.67244 2

Bucher, R. (1957). Blame and Hostility in Disaster. American Journal of Sociology, 62(5), 467-475. Retrieved from http://www.jstor.org/stable/2773239

Caragea, C. ., Squicciarini, A. ., Stehle, S. ., Neppalli, K. ., \& Tapia, A. . (2014). Mapping moods: Geo-mapped sentiment analysis during hurricane sandy. In ISCRAM 2014 Conference Proceedings - 11th International Conference on Information Systems for Crisis Response and Management (pp. 642-651). Retrieved from http:// www.iscram.org/legacy/ISCRAM2014/papers/p29.pdf

Crooks, A., Croitoru, A., Stefanidis, A., \& Radzikowski, J. (2013). \#Earthquake: Twitter as a Distributed Sensor System. Transactions in GIS, 17(1), 124-147. https://doi. org/10.1111/j.1467-9671.2012.01359.x

Freberg, K., \& Palenchar, M. J. (2013). The convergence of Digital Negotiation and Risk Challenges: strategic Implications of Social Media for Risk and Crisis Communications. In H. S. N. Al-Deen \& J. A. Hendricks (Eds.), Social Media and Strategic Communications (I, pp. 83-100). New York: PALGRAVE MACMILLAN.

Houston, J. B., Hawthorne, J., Perreault, M. F., Park, E. H., Hode, M. G., Halliwell, M. R., ... Griffith, S. a. (2014) Social media and disasters: a functional framework for social media use in disaster planning, response, and research. Disasters, 39(1), 1-22. https://doi.org/10.1111/ disa. 12092

Jaeger, P. T., Shneiderman, B., Fleischmann, K. R., Preece, J., Qu, Y., \& Fei Wu, P. (2007). Community response grids: E-government, social networks, and effective emergency management. Telecommunications Policy, 31(10-11), 592-604. https://doi.org/10.1016/j.telpol.2007.07.008

Keim, M. E., \& Noji, E. (2011). Emergent use of social media: a new age of opportunity for disaster resilience. American Journal of Disaster Medicine, 6(1), 47. https:// doi.org/10.5055/ajdm.2010.0000

Kongthon, A., Haruechaiyasak, C., Pailai, J., \& Kongyoung, S. (2014). The Role of Social Media During a Natural
Disaster: A Case Study of the 2011 Thai Flood. In International Journal of Innovation and Technology Management (Vol. 11, p. 1440012). https://doi. org/10.1142/S0219877014400124

Kumar, S., Barbier, G., Ali Abbasi, M. A., \& Liu, H. (2011). TweetTracker: An Analysis Tool for Humanitarian and Disaster Relief. In Fifth International AAAI Conference on Weblogs and Social Media (pp. 661-662). https://doi. org/10.1145/1935826.1935854

Lindsay, B. R. (2011). Social Media and Disasters: Current Uses, Future Options and Policy Considerations. Congressional Research Service Reports. https://doi.org/R41987

Lobb, A., Mock, N., \& Hutchinson, P. L. (2012). Traditional and social media coverage and charitable giving following the 2010 earthquake in Haiti. Prehospital and Disaster Medicine, 27(4), 319-324. https://doi.org/10.1017/ S1049023X12000908

Lock, R., Cooke, L., \& Jackson, T. (2013). Online Social Networking, Order and Disorder. Electronic Journal of E-Government, 11(2), 229-240.

Lundgren, R.E., \&McMakin, A.H.(2009). Riskcommunication: A handbook for communicating environmental, safety, and health risks. (L. Hanzo, Ed.) (IV). New Jersey: Wiley.

Mirza, M. (2003). Climate change and extreme weather events: can developing countries adapt? Climate Policy, 3(3), 233-248. https://doi.org/10.1016/S14693062(03)00052-4

Miyabe, M., Miura, A., \& Aramaki, E. (2012). Use trend analysis of twitter after the great east japan earthquake. In a conference on computer supported cooperative work companion (pp. 175-178). Seattle. https://doi. org/10.1145/2141512.2141571

Murthy, D., \& Longwell, S. A. (2013). TWITTER AND DISASTERS: The uses of Twitter during the 2010 Pakistan floods. Information Communication and Society, 16(6), 837-855. https://doi.org/10.1080/1369118X.2012. 696123

Qu, Y., Huang, C., Zhang, P., \& Zhang, J. (2011). Microblogging after a major disaster in China. In Proceedings of the ACM 2011 conference on Computer supported cooperative work - CSCW' 11 (p. 25). https:// doi.org/10.1145/1958824.1958830

Rive, G., Hare, J., Thomas, J., \& Nankivell, K. (2012). Social Media in an Emergency: A Best Practice Guide. Opus. Welington: Wellington Region CDEM Group.

Sakaki, T., Okazaki, M., \& Matsuo, Y. (2010). Earthquake Shakes Twitter Users: Real-time Event Detection by Social Sensors. In Proceedings of the 19th International Conference on World Wide Web (pp. 851-860). https:// doi.org/10.1145/1772690.1772777

Shklovski, I., Palen, L., \& Sutton, J. (2008). Finding Community Through Information and Communication Technology During Disaster Events. In ACM Conference on Computer Supported Cooperative Work. https://doi. org/10.1145/1460563.1460584

Simon, T., Goldberg, A., Aharonson-Daniel, L., Leykin, D., \& Adini, B. (2014). Twitter in the crossfire - The use of social media in the Westgate mall terror attack in Kenya. PLoS ONE, 9(8). https://doi.org/10.1371/journal. pone. 0104136

Takahashi, B., Tandoc, E. C., \& Carmichael, C. (2015). Communicating on Twitter during a disaster: An analysis of tweets during Typhoon Haiyan in the Philippines. 
Computers in Human Behavior, 50, 392-398. https://doi. org/10.1016/j.chb.2015.04.020

Vieweg, S., Hughes, A. L., Starbird, K., \& Palen, L. (2010). Microblogging During Two Natural Hazards Events: What Twitter May Contribute to Situational Awareness. In Proceedings of the 28th international conference on Human factors in computing systems - CHI '10. https:// doi.org/10.1145/1753326.1753486
Xiao, Y., Huang, Q., \& Wu, K. (2015). Understanding social media data for disaster management. Natural Hazards, 79(3), 1663-1679. https://doi.org/10.1007/s11069-0151918-0

Zhu, Y. Q., \& Kindarto, A. (2016). A garbage can model of government IT project failures in developing countries: The effects of leadership, decision structure and team competence. Government Information Quarterly, 33(4), 629-637. https://doi.org/10.1016/j.giq.2016.08.002 